\title{
Using GNSS radio occultation data to derive critical frequencies of the ionospheric sporadic Elayer in real time
}

\author{
Bingkun $\mathrm{Yu}^{1,2} \oplus \cdot$ Christopher J. Scott ${ }^{1} \cdot$ Xianghui Xue $^{2,3,4} \cdot$ Xinan Yue $^{5} \cdot$ Xiankang Dou $^{2}$
}

Received: 27 February 2020 / Accepted: 26 October 2020

(c) The Author(s) 2020

\begin{abstract}
The small-scale electron density irregularities in the ionosphere have a significant impact on the interruptions of Global Navigation Satellite System (GNSS) navigation and the accuracy of GNSS positioning techniques. The sporadic ionospheric E (Es) layer significantly contributes to the transient interruptions of signals (loss of lock) for GNSS tracking loops. These effects on the GNSS radio occultation (RO) signals can be used to derive the global location and intensity of Es layers as a complement to ground-based observations. Here we conduct statistical analyses of the intensity of Es layers, based on the scintillation index S4max from the FORMOSAT-3/COSMIC during the period 2006-2014. In comparison with simultaneous observations from an ionosonde network of five low-to-middle latitude ionosondes, the S4max indices from COSMIC, especially the small values, are linearly related to the critical frequency of Es layers ( $\left.f_{0} E s\right)$. An accumulated period of less than $1 \mathrm{~h}$ is required to derive the short-term variations in real-time ionospheric Es layers. A total of $30.22 \%, 69.57 \%$ and $98.13 \%$ coincident hourly $\mathrm{f}_{\mathrm{o}}$ Es values have a relative difference less than $10 \%, 30 \%$ and $100 \%$. Overall, the GNSS RO measurements have the potential to provide accurate hourly observations of Es layers. Observations with $\mathrm{S} 4 \mathrm{max}<0.4$ ( $\mathrm{f}_{0} \mathrm{Es}<3.6 \mathrm{MHz}$ ), accounting for $66 \%$ of COSMIC S4 measurements, have not been used fully previously, as they are not easily visible in ground-based ionosonde data.
\end{abstract}

Keywords Global navigation satellite system · Radio occultation · FORMOSAT-3/COSMIC · S4index · Ionosphere · Ionospheric irregularities $\cdot$ Sporadic $\mathrm{E} \cdot$ Ionosonde $\cdot$ foEs $\cdot$ Criticalfrequency

Bingkun Yu

bingkun.yu@ reading.ac.uk

$\triangle$ Xianghui Xue

xuexh@ustc.edu.cn

1 Department of Meteorology, University of Reading, Berkshire, UK

2 CAS Key Laboratory of Geospace Environment, Department of Geophysics and Planetary Sciences, University of Science and Technology of China, Hefei, Anhui, China

3 Anhui Mengcheng Geophysics National Observation and Research Station, University of Science and Technology of China, Mengcheng, Anhui, China

4 CAS Center for Excellence in Comparative Planetology, Hefei, China

5 Key Laboratory of Earth and Planetary Physics, Institute of Geology and Geophysics, Chinese Academy of Sciences, Beijing, China

\section{Introduction}

Electron-density irregularities in the ionosphere can have a significant impact on the performance of the Global Navigation Satellite System (GNSS). When the GNSS radio waves propagate through the ionosphere, the ionospheric irregularities will introduce phase shift and amplitude fluctuations in signals, which is the key factor in the loss of GNSS signal reception or unacceptable accuracy issues (Coster and Komjathy 2008). A loss of lock on GNSS satellites can seriously influence the accuracy and further application of precise point positioning in real time. Interruptions of GNSS signal tracking due to ionospheric effects occur approximately 23\% per occultation (Yue et al. 2016). Among these ionospheric irregularities, the sporadic E (Es) layer is of particular interest. Es is a thin layer composed of intense long-live metallic plasma at 90-130 km altitude (Plane et al. 2015, 2018), concentrated through vertical convergence resulting from wind shear (Davis and Johnson 2005; Jacobi et al. 2019). The Es layers cause approximately $8.3 \%$ interruptions of 
GNSS signals per occultation, which contribute more than a third to the influence of ionospheric plasma irregularities on tracking interruptions of GNSS (Yue et al. 2016). Recently, an Es layer was found to exist in the Martian ionosphere (Collinson et al. 2020), which highlights the importance of understanding the Es layer to the long-distance radio communications for planetary exploration.

The ionospheric influence on the amplitude and phase of radio occultation ( $\mathrm{RO}$ ) signals can be used to derive the ionospheric scintillation index (Yeh and Liu 1982; Li et al. 2008). This allows scintillation information to be applied to research into the global map of Es layers. In past decades, the scintillations of GNSS-RO measurements have been widely employed to study the occurrence of Es layers (EsOR). Wu et al. (2005) investigated the global morphology of Es layers from CHAMP RO observations. Arras et al. (2008) presented a high-spatial-resolution global map of EsOR. The global climatology of EsOR was further confirmed by Yeh et al. (2012), Chu et al. (2014), and Tsai et al. (2018). The climatology of EsOR (Dou et al. 2010) and short-term variability of ten minutes to one hour in the Es layer (Xue et al. 2017; Ma et al. 2019) in a local geographic region can be measured by $\mathrm{RO}$ signals. The maximum values of the amplitude scintillation S4 index (S4max) derived from $50 \mathrm{~Hz}$ L1 amplitude measurements, which occur at the altitude of Es, can be used as a proxy of the intensity of Es layers (Yue et al. 2015a). Recently, Yu et al. (2019a, 2020) present an investigation into the global climatology of the relative intensities of Es layers, based on the S4 index of the FORMOsa SATellite mission-3/Constellation Observing System for Meteorology, Ionosphere and Climate (FORMOSAT-3/COSMIC). Furthermore, the successful launch of six satellites on a SpaceX Falcon Heavy rocket for the FORMOSAT-7/COSMIC-2 (COSMIC-2) mission will soon enable improved capability of global ionospheric Es layer observations with the high quality and quantity of GNSS RO measurements (Hsu et al. 2018). Through development of GNSS technology, a dramatically growing number of RO measurements can provide global coverage with a high spatial resolution. Previous studies have used the S4 scintillation index as a proxy for Es layers (Arras et al. 2008; Yue et al. 2015a; Yu et al. 2019a). However, it is difficult to determine how well the $\mathrm{S} 4$ index corresponds to an Es layer observed by an ionospheric sounder (ionosonde) or radar, and whether it can be used to infer the intensity of Es layers on a global scale. It is necessary to quantitatively characterize global observations of Es layers based on the scintillation index S4max from satellite measurements by comparison with ground-based observations of the peak Es plasma frequency, $\mathrm{f}_{\mathrm{o}} \mathrm{Es}$. The scope of this study is to assess the statistical difference between $\mathrm{S} 4$ index and $\mathrm{f}_{\mathrm{o}} \mathrm{Es}$ by ionosondes. We present statistical analyses of numerous datasets into the relationship between the observations of Es layers from $\mathrm{S} 4$ index obtained by the COSMIC satellites and manual-scaled $\mathrm{f}_{\mathrm{o}}$ Es data from a chain of ground-based ionosonde stations.

\section{Data and method}

The COSMIC mission is a low-earth-orbit (LEO) constellation of six identical microsatellites launched from Vandenberg Air Force Base on April 15, 2006, which collects global remote sensing data of the atmosphere and ionosphere by measuring changes in radio signals (Schreiner et al. 2007). The six satellites were initially spaced sequentially in the same orbit at $512 \mathrm{~km}$ and subsequently raised to orbits at $800 \mathrm{~km}$ in the following 17 months. The COSMIC mission is capable of measuring 2000-2500 RO profiles per day, distributed nearly evenly in local solar time (Yue et al. 2014, 2015b). Thus, the ionospheric measurements from the COSMIC satellites provide an opportunity to derive highspatial-resolution observations of Es layers on a global scale. The amplitude of the S4 index is one of the most important parameters in the scintillation data, defined as the standard deviation of the normalized signal intensity (Briggs and Parkin 1963). Unlike the E layers formed mainly by the direct photoionization of $\mathrm{N}_{2}$ and $\mathrm{O}_{2}$ in the day, the Es layers are relatively intense plasma density irregularities (Arras 2010). The plasma irregularities are formed when the long-live metallic ions are converged vertically towards a thin layer by the wind shear mechanisms, producing an enhancement of intense electron density with a plasma density fluctuation and a sharp vertical electron density gradient. The Es layers scatter, refract, or reflect incident HF/VHF radio waves (Whitehead 1989).

The S4max is the maximum value of S4 index, denoting an amplitude scintillation index in the GNSS RO signals. Large S4 indices occurring at altitudes of 90-130 km are related to the occurrence of Es layers (Yue et al. 2015a; Yu et al. 2019a, 2020). In this study, the intensity of Es layers, represented by the continuous 24-h recording of S4max in RO data from the COSMIC satellites, was compared with the critical frequency of the Es layers, $f_{0} E s$, observed with ground-based ionosondes. A total of 5,795,649 S4max indices were analyzed with tangential altitudes of $90-130 \mathrm{~km}$ between December 2006 and January 2014.

Ground-based ionosonde data have been used to study the behavior of the ionosphere since the early 1930s and are regarded as providing reliable measurements of the intensities of Es layers over the subsequent decades (Rishbeth and Garriott 1969; Scott et al. 2016). The meteoric metals such as $\mathrm{Na}, \mathrm{Fe}$ and $\mathrm{Ca}$ atoms in the earth's mesosphere and lower thermosphere at $80-110 \mathrm{~km}$ altitude are most likely associated with the long-live metallic ions within Es layers (Cai et al. 2019; Xun et al. 2020). The frequency of the ionized plasma in Es layers is widely used to investigate 
the seasonal and local time variations in metallic ions in the earth's upper atmosphere (Yuan et al. 2014; Yu et al. 2019b). The ionized plasma in Es layers can be characterized by the critical frequency $\mathrm{f}_{\mathrm{o}} \mathrm{Es}$ (in $\mathrm{Hz}$ ), which is related to the peak electron concentration of the Es layer, $\mathrm{N}_{\mathrm{e}}$ (in $\mathrm{m}^{-3}$ ), by the formula $f_{o} E s=8.98 \sqrt{N_{e}}($ Davis and Lo 2008). In this study, an ionosonde network consists of a meridional chain of low-to-middle latitude ionosonde stations, which include Digital Portable Sounder 4D (DPS4D) digital ionosondes (digisondes) (Bibl and Reinisch 1978) at Sanya $\left(18.3^{\circ} \mathrm{N}, 109.4^{\circ} \mathrm{E}\right)$, Shaoyang $\left(27.1^{\circ} \mathrm{N}, 111.3^{\circ} \mathrm{E}\right)$, Wuhan $\left(30.5^{\circ} \mathrm{N}, 114.4^{\circ} \mathrm{E}\right)$, Beijing $\left(40.3^{\circ} \mathrm{N}, 116.2^{\circ} \mathrm{E}\right)$, Mohe $\left(52.0^{\circ} \mathrm{N}, 122.5^{\circ} \mathrm{E}\right)$, located roughly along a line at $120^{\circ} \mathrm{E}$ longitude, and is part of the Chinese Meridian Project (Wang 2010). The $f_{o}$ Es values, which were measured every hour, were manually scaled using the SAO Explorer software (Hu et al. 2014).

In this study, we compared these ground-based measurements with COSMIC S4max data obtained from within a square area of $5^{\circ}$ latitude and $5^{\circ}$ longitude centered on each ionosonde. The time resolution of the manual-scaled ionospheric data is $1 \mathrm{~h}$ so $\mathrm{S} 4 \mathrm{max}$ values occurring in this area were hourly averaged to represent the simultaneous information on the intensities of Es layers from COSMIC satellites. This yielded 12,761 hourly COSMIC S4max and 67,423 hourly manual-scaled $\mathrm{f}_{\mathrm{o}}$ Es data points in total for five ionosonde stations.

\section{Results}

Figure 1 shows the daily mean S4max from COSMIC within $\pm 2.5^{\circ}$ latitude and longitude of an ionosonde at Beijing and the 5-day smoothed daily mean $\mathrm{f}_{\mathrm{o}}$ Es measured by the ionosonde between 2006 and 2014. The climatological variations in Es layers represented by the S4max derived from the COSMIC RO signals correspond well with the independent ionosonde observations. Note that the S4max is the maximum amplitude of GNSS-RO fluctuations caused by vertical electron density gradients of the Es layer, and $\mathrm{f}_{\mathrm{o}}$ Es is the maximum radio frequency of sounding pulses that Es layers can reflect vertically as a measure of the densest ionization within the Es layer.

Though Yu et al. (2019a) have investigated the global climatology of the intensity of Es layers on the basis of COSMIC S4max data, the relation between S4max and $\mathrm{f}_{0}$ Es has not been well studied. The blanketing frequency $\mathrm{f}_{\mathrm{b}}$ Es corresponds to the lowest frequency that can penetrate the Es layer, so it is a measure of the weakest patches of ionization (Yu et al. 2015). Arras and Wickert (2018) revealed a linear relationship between $S 4$ max and $\mathrm{f}_{b}$ Es based on 17 coinciding measurements at mid-latitudes, which is consistent with the results over the Brazilian low-latitude region (Resende et al. 2018). Whalen (2009) quantified 47 determinations of S4max, which have a linear dependence on the coinciding electron density (equivalently, the square of the electron plasma frequency $\mathrm{f}^{2}$ ). These results were inferred from a small number of observations and a single location. To make statistical analysis, we compared a total of 2848 hourly pairs of observations to investigate whether the $\mathrm{S} 4 \mathrm{max}$ is a linear function of $\mathrm{f}_{\mathrm{o}} \mathrm{Es}$ or $\mathrm{f}_{\mathrm{o}} \mathrm{Es}^{2}$. We found 974, 206, 333, 834 and 501 simultaneous pairs of hourly S4max and hourly $\mathrm{f}_{\mathrm{o}} \mathrm{Es}$ for Sanya, Shaoyang, Wuhan, Beijing and Mohe ionosonde stations, respectively.

Figure 2 contains three rows showing the scatter plots of COSMIC S4max values versus $\mathrm{f}_{\mathrm{o}}$ Es values for all 2848 pairs, 2003 pairs without the occurrence of background $\mathrm{E}$ layers, and 845 pairs with the occurrence of E layers. Figure 2a shows the comparison of the observed COSMIC $\mathrm{S} 4 \mathrm{max}$ with $\mathrm{f}_{\mathrm{o}}$ Es from each ionosonde (distinguished by the color and shape of dots). Figure $2 b$ shows a density scatter plot with both linear and quadratic curves fitted using
Fig. 1 Time series of S4max from COSMIC satellites and $\mathrm{f}_{\mathrm{o}}$ Es measured by the ionosonde at Beijing $\left(40.3^{\circ} \mathrm{N}, 116.2^{\circ} \mathrm{E}\right)$ during 2006-2014. The daily mean S4max between 90 and $130 \mathrm{~km}$ altitude from COSMIC $\mathrm{RO}$ measurements within $\pm 2.5^{\circ}$ latitude and longitude of the ionosonde station is shown as green points, and the 5-day smoothed daily mean $\mathrm{f}_{0} \mathrm{Es}$ is shown as a black line

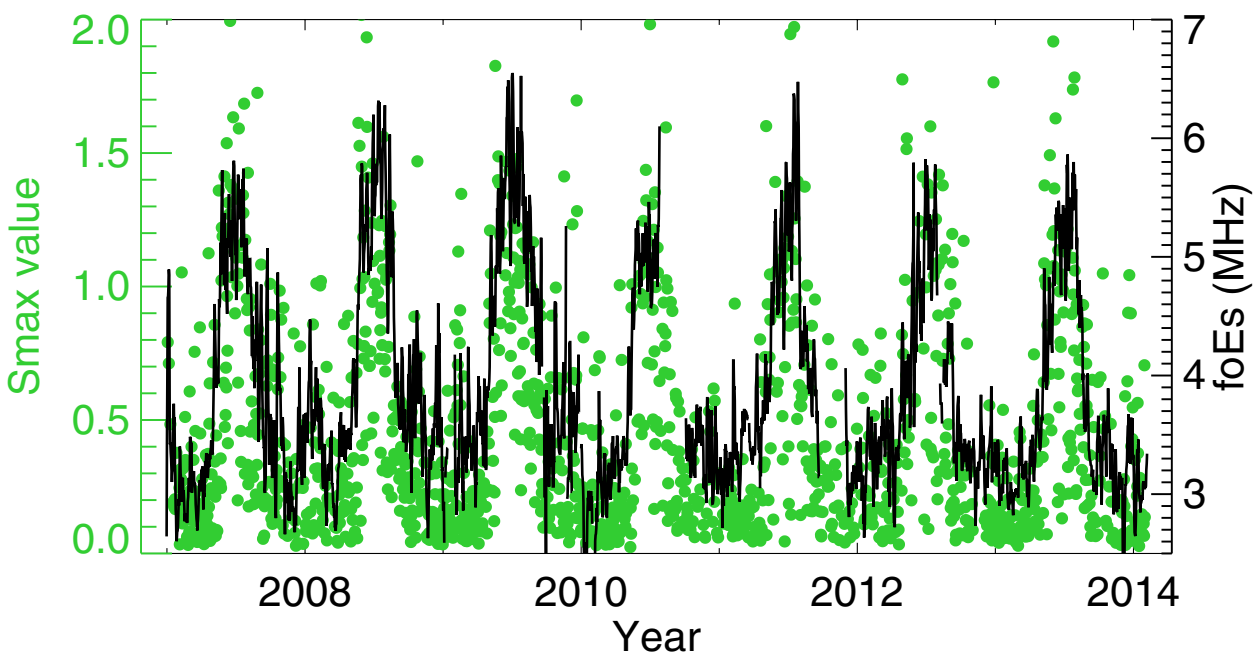


Fig. 2 Scatter plots of hourly $\mathrm{f}_{\mathrm{o}}$ Es observed by an ionosonde network of five low-to-middle latitude DPS4D ionosondes versus the coincident hourly COSMIC RO S4max values. a Comparison between COSMIC S4max and $f_{0}$ Es from each ionosonde distinguished by the color and shape of dots. b Density scatter plot with fitting curves. The violet line represents the linear fitting between $\mathrm{f}_{\mathrm{o}}$ Es and $\mathrm{S} 4 \mathrm{max}$ by the least-squares equation $f_{o} E s=2.81+2.02 \times S 4 \max$. The black line represents the linear fitting between $\mathrm{f}_{\mathrm{o}} \mathrm{Es}^{2}$ and $\mathrm{S} 4 \mathrm{max}$ by the least-squares equation $f_{o}^{2} E s=6.64+19.55 \times S 4 \max$. $\mathbf{c}$ and $\mathbf{d}$ Comparison between COSMIC S4max and $\mathrm{f}_{0} \mathrm{Es}$ without the occurrence of $\mathrm{E}$ layers. The fitting results are $f_{o} E s=2.77+2.06 \times S 4 \max$ (violet) and

$f_{o}^{2} E s=6.36+20.13 \times S 4 \max$ (black). e and $\mathbf{f}$ Comparison between COSMIC S4max and $\mathrm{f}_{\mathrm{o}}$ Es with $\mathrm{E}$ layers present. The fitting results are $f_{o} E s=2.87+1.91 \times S 4 \max$ (violet) and

$f_{o}^{2} E s=7.27+17.84 \times S 4 \max$ (black)
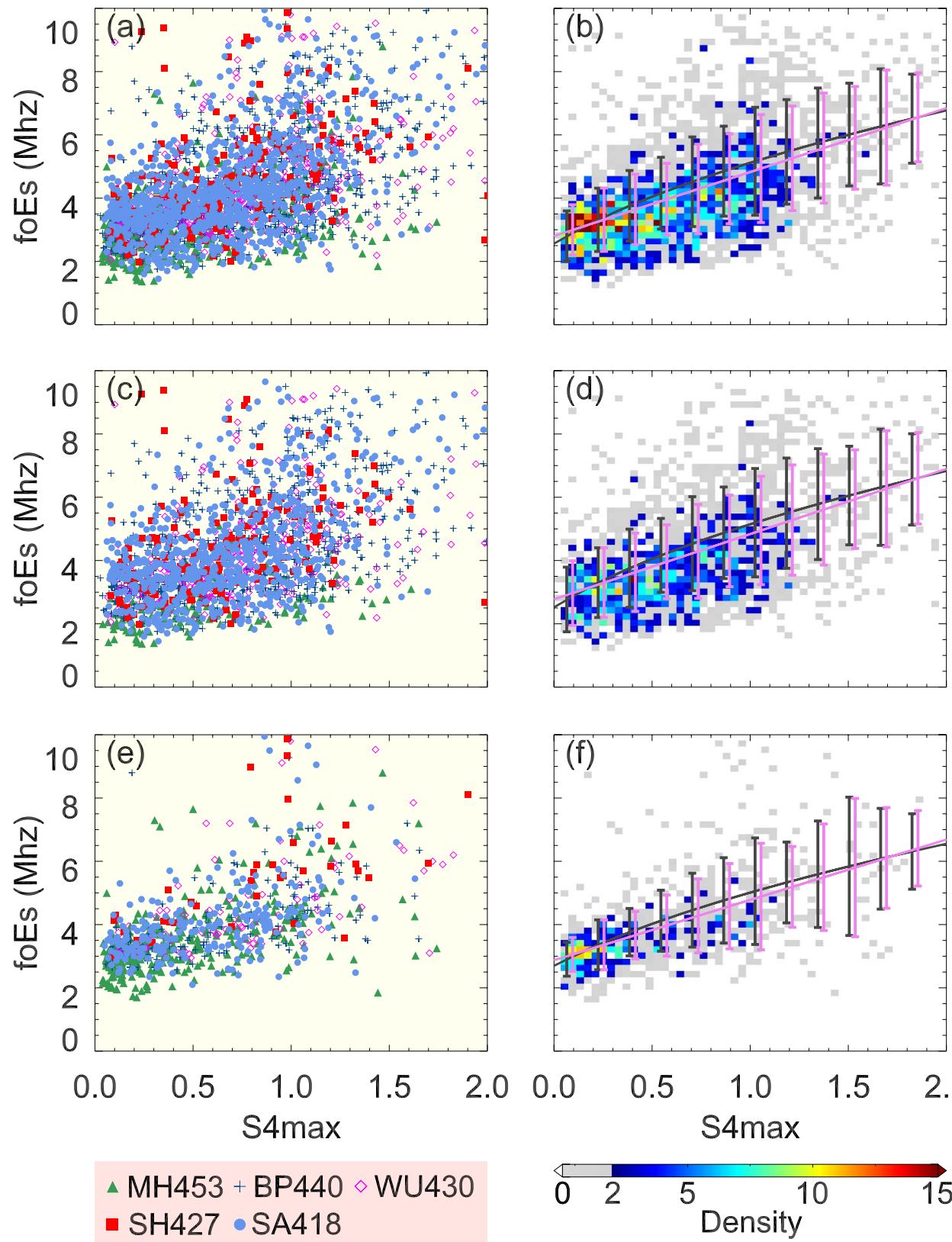
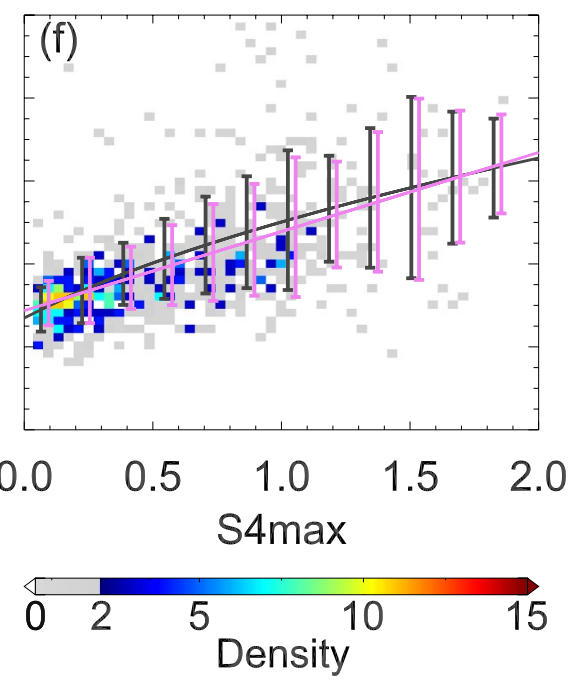

a least-square method. A linear relationship (correlation coefficient: $r=0.53$ ) between $\mathrm{S} 4$ max and $\mathrm{f}_{\mathrm{o}}$ Es was found to be $f_{o} E s=2.81+2.02 \times S 4 \max$, and its least square fit is represented as a violet line with its uncertainty represented by the standard deviation. The $p$-value (calculated to test the hypothesis that two datasets are independent) is less than 0.01 . The black line represents a linear fit between $\mathrm{S} 4 \mathrm{max}$ and $\mathrm{f}_{\mathrm{o}} \mathrm{Es}^{2}$, which is $f_{o}^{2} E s=6.64+19.55 \times S 4 \max (r=0.50$, $p<0.01$ ). Note that the correlation might be influenced due to the special observational geometry of RO measurements (Zeng and Sokolovskiy 2010) and local ionospheric variability within $1 \mathrm{~h}$.

Some unusually large S4max values may be induced by the defocusing of GNSS signals through the reflection/ refraction in E layers rather than the fluctuations caused by Es layers (Ko and Yeh 2010). In order to separate the effect of $E$ layers, the analyses were repeated but excluding any events in which there were simultaneous observations of critical frequency of $\mathrm{E}$ layers $\left(\mathrm{f}_{\mathrm{o}} \mathrm{E}\right)$ by ionosondes. Figure $2 c, d$ shows the result of measurements without the occurrence of $\mathrm{E}$ layers. The relationship between $\mathrm{S} 4 \mathrm{max}$ and $\mathrm{f}_{\mathrm{o}} \mathrm{Es}$ can be given by the least square fitting as $f_{o} E s=2.77+2.06 \times S 4 \max (r=0.51, p<0.01)$ and $f_{o}^{2} E s=6.36+20.13 \times S 4 \max (r=0.48, p<0.01)$.

The Es layer sometimes overlaps with the background E layer. Therefore, Es can be difficult to identify through manual scaling of an ionogram under these circumstances. Figure 2e, f shows the result of observations 
with the existence of $\mathrm{E}$ layers. The relationship between S4max and $\mathrm{f}_{\mathrm{o}}$ Es can be derived by the least square fitting as $f_{o} E s=2.87+1.91 \times S 4 \max (r=0.58, p<0.01)$ and $f_{o}^{2} E s=7.27+17.84 \times S 4 \max (r=0.53, p<0.01)$.

The estimates of $\mathrm{f}_{\mathrm{o}} \mathrm{Es}$ from the COSMIC S4max can be given by using the fitting curves plotted in Fig. 2b. Figure 3 shows the comparisons for two fitting methods, respectively. The top and bottom panels show the scatter plots of the $\mathrm{f}_{\mathrm{o}} \mathrm{Es}$ from ionosondes and estimated $\mathrm{f}_{\mathrm{o}}$ Es from COSMIC by the equation $f_{o}^{2} E s=6.64+19.55 \times S 4 \max$ and the equation $f_{o} E s=2.81+2.02 \times S 4$ max.

Figure 4 shows the statistical results of the absolute and relative differences between $\mathrm{f}_{0} \mathrm{Es}$ from ionosondes and COSMIC S4max by using two fitting methods. Figure $4 a$, c gives
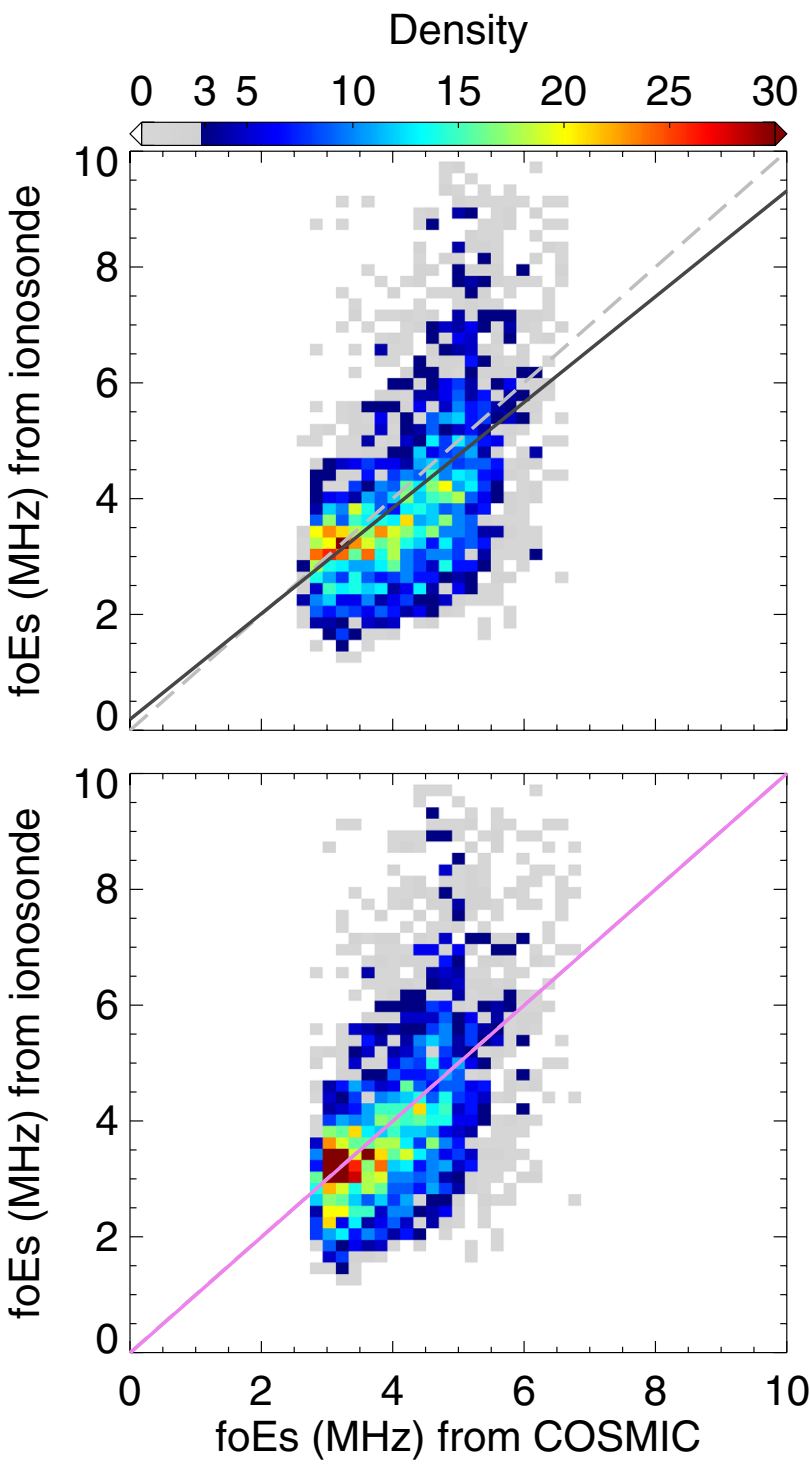

Fig. 3 Density scatter plot of the $\mathrm{f}_{\mathrm{o}} \mathrm{Es}$ from ionosondes and estimated $\mathrm{f}_{0}$ Es from COSMIC by the equation $f_{0}^{2} E s=6.64+19.55 \times S 4 \max$ (top) and the equation $f_{o} E s=2.81+2.02 \times S 4 \max$ (bottom) the statistical results by the least-square equation $f_{o}^{2} E s=6.64+19.55 \times S 4 \max$. The absolute difference of $\mathrm{f}_{\mathrm{o}} \mathrm{Es}\left(f_{\text {COSMIC }}-f_{\text {ionosonde }}\right)$ shows a typical Gaussian distribution. The mean and the root-mean-square error (RMSE) of the absolute difference are $0.19 \mathrm{MHz}$ and $1.33 \mathrm{MHz}$ between the $\mathrm{f}_{\mathrm{o}}$ Es derived from COSMIC S4max and the observed $\mathrm{f}_{\mathrm{o}} \mathrm{Es}$ by ionosondes. The relative difference of $\mathrm{f}_{\mathrm{o}} \mathrm{Es}$ $\left(\frac{f_{\text {Cosmic }}-f_{\text {inossonde }}}{f_{\text {ionosonde }}}\right)$ shows that $28.78 \%$ coincident $\mathrm{f}_{\mathrm{o}}$ Es values have a relative difference less than $10 \%$. A total of $66.57 \%$ coincident $\mathrm{f}_{\mathrm{o}}$ Es values have a relative difference less than $30 \%$, and $97.36 \%$ coincident $\mathrm{f}_{0}$ Es values have a relative difference less than $100 \%$. The mean and RMSE of the relative difference are $14.23 \%$ and $35.72 \%$.

The comparison of the manual-scaled $\mathrm{f}_{\mathrm{o}}$ Es from ionosonde measurements and the COSMIC $\mathrm{f}_{\mathrm{o}}$ Es estimated by the equation $f_{o} E s=2.81+2.02 \times S 4$ max is shown in Fig. $4 \mathrm{~b}$, d. The absolute difference of $\mathrm{f}_{\mathrm{o}}$ Es shows a Gaussian distribution with a mean of $0 \mathrm{MHz}$ and an RMSE of $1.32 \mathrm{MHz}$. A total of $30.22 \%, 69.57 \%$ and $98.13 \%$ coincident $\mathrm{f}_{\mathrm{o}}$ Es values have a relative difference less than $10 \%, 30 \%$ and $100 \%$. The mean and RMSE of the relative difference are $9.51 \%$ and $33.82 \%$.

From the scatter plots and the statistics of differences between the estimated hourly $\mathrm{f}_{\mathrm{o}}$ Es from COSMIC and hourly $\mathrm{f}_{\mathrm{o}}$ Es from the ground-based ionosondes, $\mathrm{S} 4 \mathrm{max}$ is more dependent on $\mathrm{f}_{\mathrm{o}}$ Es than $\mathrm{f}_{\mathrm{o}} \mathrm{Es}^{2}$. Figure 5 shows a comparison of daily $\mathrm{f}_{\mathrm{o}} \mathrm{Es}$ from the ionosonde observations at Beijing (grey) with the estimated $\mathrm{f}_{\mathrm{o}}$ Es from COSMIC S4max by using two equations $f_{o}^{2} E s=6.64+19.55 \times S 4$ max (black) and $f_{o} E s=2.81+2.02 \times S 4 \max$ (violet).

The number of $\mathrm{f}_{\mathrm{o}}$ Es co-observed hourly measurements is 2848 , which accounts for $23 \%$ of 12,761 hourly measurements accumulated from 5,795,649 COSMIC S4max measurements. Strong Es layers are preferentially identified in ionograms since weak layers are more difficult to be identified clearly from background noise. An Es layer can be identified in ionograms when its frequency is above the minimum frequency detected by the ionosonde. This threshold is a function of transmitter and receiver characteristics and, for the instrumentation used in this study, lies between 1.0 and $1.5 \mathrm{MHz}$ (Haldoupis 2011). The GNSS RO technique has the advantage of high vertical resolution, the absence of multi-path disturbances of reflected signals in the lower atmosphere, and global coverage. Nonetheless, the RO measurements are more efficient at detecting weak Es layers than strong Es layers since exceptionally sharp electron density gradients can cause interruptions in GNSS signal tracking (Yue et al. 2016). The blue line in Fig. 6 represents variations in the ratio of the COSMIC and coobserved measurements. The ratio ranges from 49 to around 4 when the S4max is less than 0.4. Therefore, the GNSS $\mathrm{RO}$ technique is particularly useful to provide the real-time 
Fig. 4 Statistical results of the difference between $\mathrm{f}_{\mathrm{o}} \mathrm{Es}$ from ionosondes and $\mathrm{f}_{\mathrm{o}} \mathrm{Es}$ estimated from COSMIC S4max by using two fitting methods. a and $\mathbf{c}$ Statistics of absolute and relative differences between the $\mathrm{f}_{\mathrm{o}}$ Es from ionosondes and estimated $\mathrm{f}_{\mathrm{o}} \mathrm{Es}$ from COSMIC by the equation $f_{o}^{2} E s=6.64+19.55 \times S 4 \max$. $\mathbf{b}$ and $\mathbf{d}$ Statistics of absolute and relative differences between the $\mathrm{f}_{\mathrm{o}}$ Es from ionosondes and estimated $\mathrm{f}_{\mathrm{o}} \mathrm{Es}$ from COSMIC by the equation $f_{o} E s=2.81+2.02 \times S 4 \max$
Fig. 5 An example of comparison of daily $\mathrm{f}_{\mathrm{o}}$ Es derived from COSMIC S4max by using two fitting equations with the daily $\mathrm{f}_{\mathrm{o}} \mathrm{Es}$ from the ionosonde observations at one station (BP440) in the ionosonde network

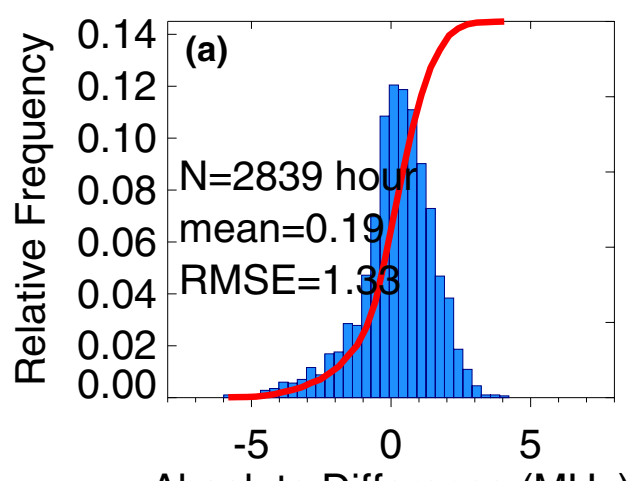

Absolute Difference $(\mathrm{MHz})$
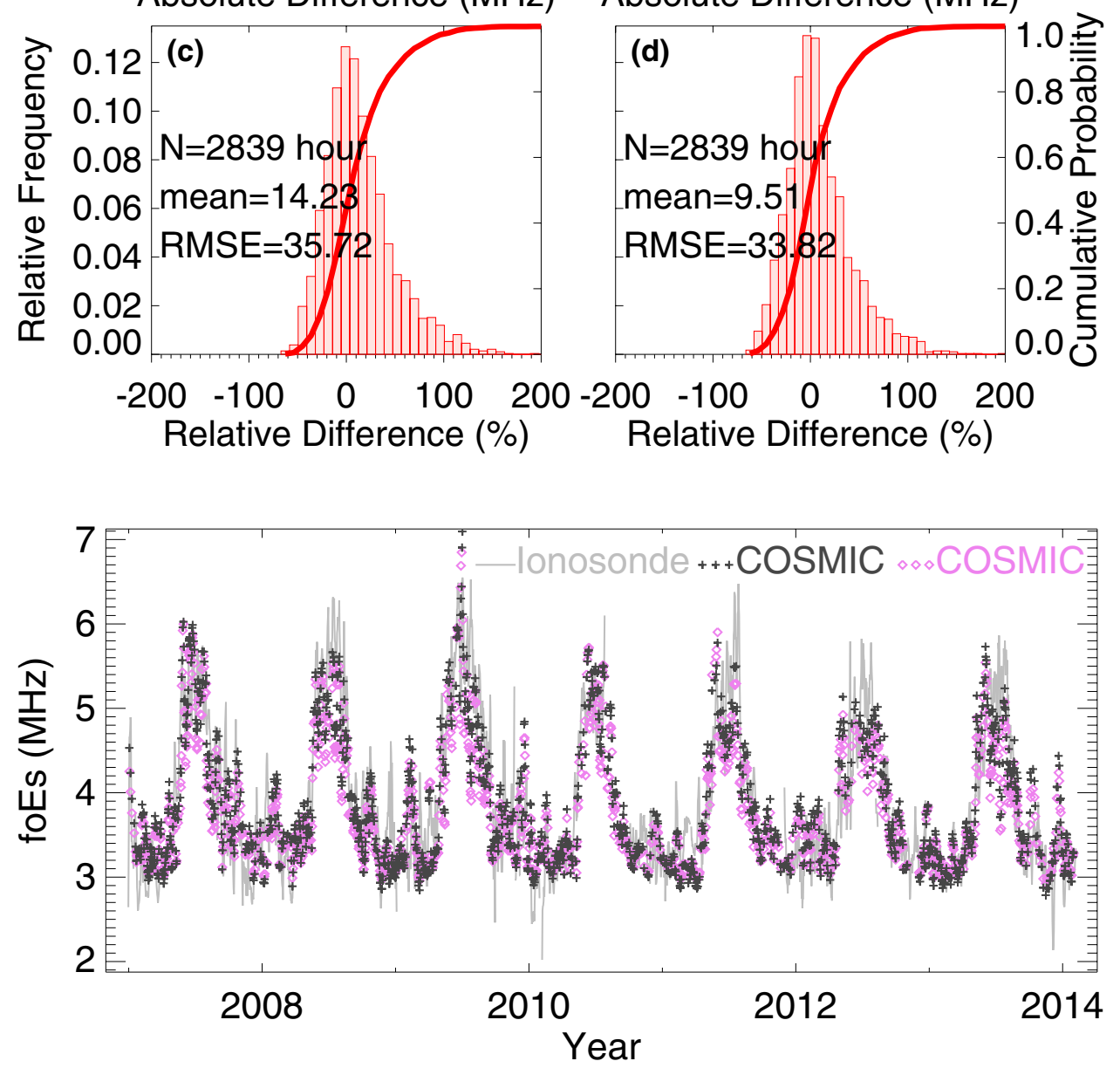

observations of Es layers over the region with rare or no coverage of ground-based ionospheric monitoring stations. In previous studies, the $S 4 \max$ was only considered to indicate an ionospheric disturbance when it exceeds an empirical threshold of 0.2-0.5 (Ray et al. 2006; Ko and Yeh 2010; Yue et al. 2015a, 2016; Arras and Wickert 2018). We found the S4max indices, especially small values, are correlated with $\mathrm{f}_{\mathrm{o}}$ Es observed by ionosondes. The number of $\mathrm{S} 4 \mathrm{max}<0.4$ accounts for $66 \%$ of the total COSMIC S4max measurements. Such a large number of accumulated RO data have not previously been applied in full to study the distribution of global Es layers. These observations are of critical
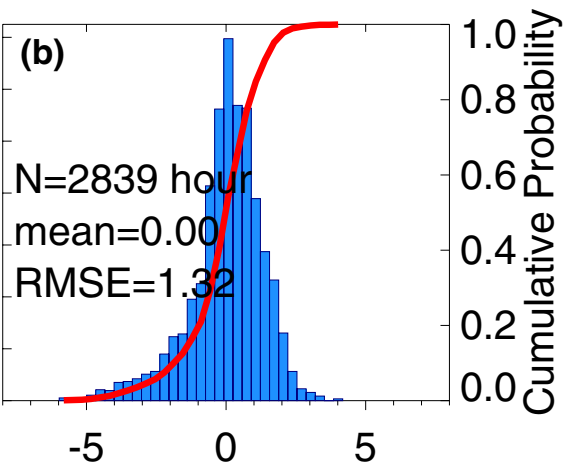

Absolute Difference $(\mathrm{MHz})$

importance to understand the morphology and distribution of Es layers as well as the ionospheric applications in satellite communications and GNSS precise point positioning.

In this study, the dependence of $\mathrm{S} 4 \mathrm{max}$ on $\mathrm{f}_{\mathrm{o}}$ Es described above is quantitatively analyzed by using manual-scaled $f_{0} E s$ data with the ionosondes of the same type. These stations are all equipped with DPS4D ionosondes, developed by the University of Massachusetts Lowell (Reinisch and Galkin 2011). To study the bias level of $f_{0}$ Es between the ionograms recorded by different types of ionosondes, we subsequently compared the manual-scaled $\mathrm{f}_{\mathrm{o}}$ Es observations at Canberra, Australia $\left(35.32^{\circ} \mathrm{S}, 149.00^{\circ} \mathrm{E}\right)$ recorded with an 


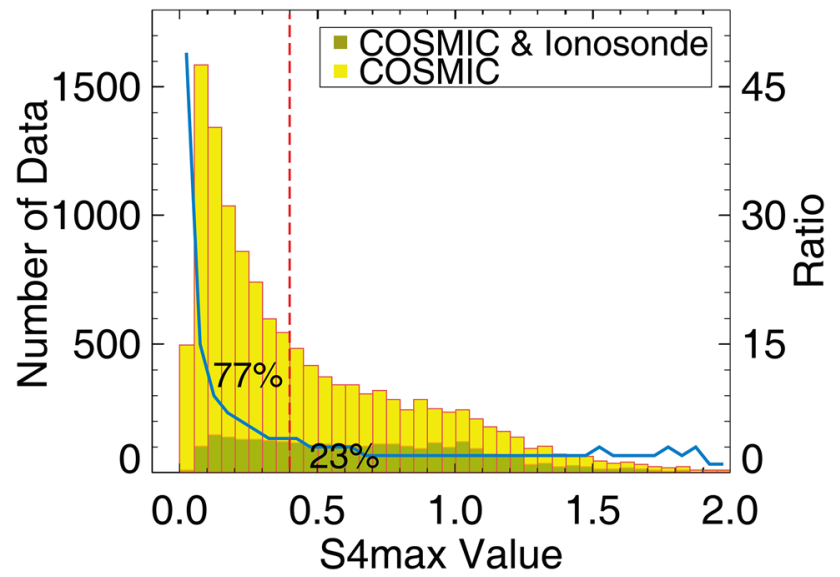

Fig. 6 Distribution of the COSMIC S4max and co-observed measurements. The blue line represents variations in the ratio of the COSMIC and co-observed measurements. The vertical red dashed line represents a threshold of 0.4 , below which the GNSS RO technique provides more observations of Es layers than ground-based ionosondes

Ionospheric Prediction Service 5A (IPS5A) digisonde, with the $\mathrm{f}_{0}$ Es determined from COSMIC S4max within $\pm 2.5^{\circ}$ latitude and longitude of this ground-based station. In Fig. 7, the climatological variations in $\mathrm{f}_{\mathrm{o}} \mathrm{Es}$ from COSMIC by the least-square equation $f_{o} E s=2.81+2.02 \times S 4 \max$ (green line) agree with $\mathrm{f}_{\mathrm{o}} \mathrm{Es}$ from the ionosonde (black line). The Canberra ionosonde data were independent (not used in the calibration). Both the measurements of $\mathrm{f}_{0}$ Es follow the same diurnal trends; however, there is a maximum bias of approximately $0.8 \mathrm{MHz}$ between the $\mathrm{f}_{\mathrm{o}}$ Es observed by the ionosonde and the COSMIC derived $\mathrm{f}_{\mathrm{o}}$ Es.

Figure 8 shows that the linear correlation coefficient between hourly $\mathrm{f}_{\mathrm{o}}$ Es derived from COSMIC and ionosonde data is 0.57 . A majority of the coincident $\mathrm{f}_{\mathrm{o}} \mathrm{Es}$ points from the ionosonde are distributed in a range of $1.5-4.0 \mathrm{MHz}$, which indicates a minimum threshold of the manual-scaled $\mathrm{f}_{\mathrm{o}}$ Es in an ionogram to be around 1.5 MHz. The distribution of $\mathrm{f}_{\mathrm{o}}$ Es measured by the Canberra IPS5A ionosonde is also presented. The number of a patch of $\mathrm{f}_{0} E s$ values is over 60 near $1.5 \mathrm{MHz}$, which is concentrated at the minimum frequency of the detection threshold by an ionosonde. This part of $f_{0}$ Es values outside of the statistical distribution was not observed by all the DPS4D ionosondes in Fig. 2. The IPS5A ionosonde appears to be measuring some abnormal low values near the detection threshold, which makes the Canberra data did not match for low $\mathrm{f}_{\mathrm{o}}$ Es values. From a global-scale investigation of ionosonde parameters of Es layers, such abnormally high occurrences of foEs values could also be found near the instrumental detection limits within the frequency range $1.28-1.60 \mathrm{MHz}$ (Yu et al. 2020). It indicates that $f_{0}$ Es values are determined less reliably from ionosondes in the low frequency, as a likely result from the influence of ambient ionizations within the background $\mathrm{E}$ layers to characterize the intensity of weak Es layers.

Figure 9 shows the distributions of $\mathrm{f}_{0} E s$ and the statistical analysis of $\mathrm{f}_{0} E s$ difference. The mean and RMSE of $\mathrm{f}_{0} \mathrm{Es}$ difference are $0.44 \mathrm{MHz}$ and $1.28 \mathrm{MHz}$. There is a major distribution shift of $1.0 \mathrm{MHz}$ in $\mathrm{f}_{\mathrm{o}} \mathrm{Es}$, which may result from hardware features and ionogram scaling algorithms from the different types of ionosondes. Therefore, the global RO measurements show promise as a reference to scale and calibrate ionospheric data recorded by different ionosonde systems.

\section{Discussions}

The ionospheric irregularities within Es layers have severe impacts on the accuracy and predicting interruption of GNSS-based navigation and precise point positioning. The GNSS RO measurements are demonstrated to have the potential to provide real-time global Es layer monitoring as a complementary technique to ground-based observations. However, it is worth noting that ionospheric ground-based
Fig. 7 Daily mean $\mathrm{f}_{\mathrm{o}}$ Es from COSMIC (green line) and from ionosonde (black line) at Canberra $\left(35.32^{\circ} \mathrm{S}, 149.00^{\circ} \mathrm{E}\right)$ The Canberra ionosonde data were independent (not used in the calibration)

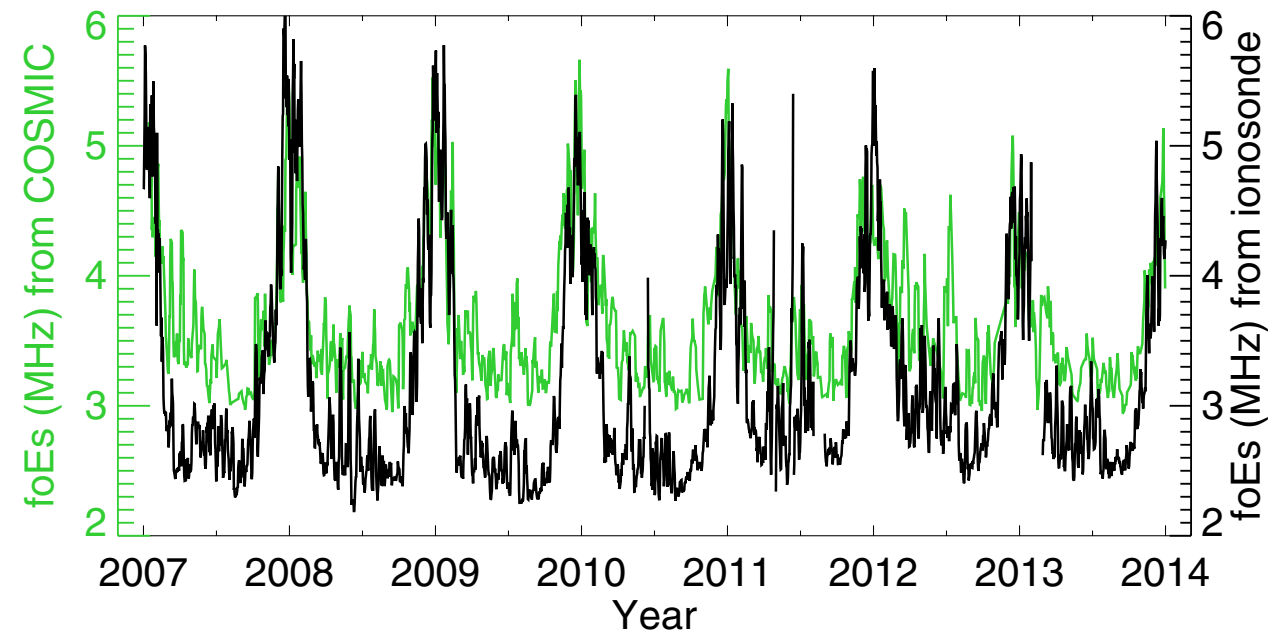




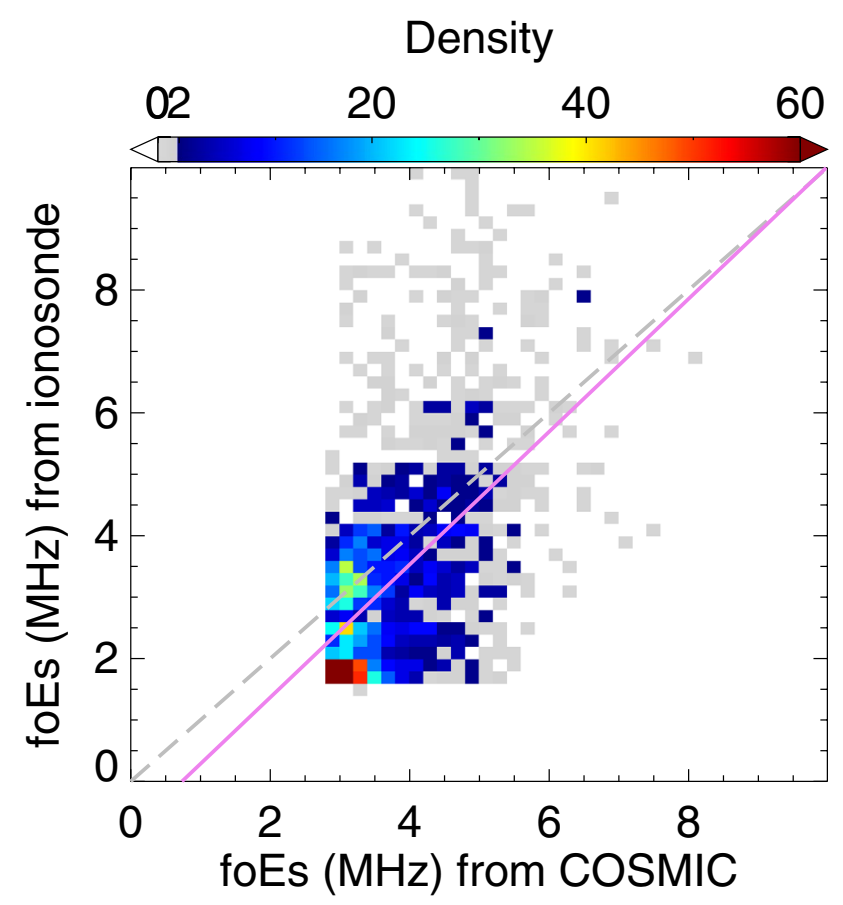

Fig. 8 Density scatter plot of hourly $\mathrm{f}_{\mathrm{o}}$ Es from COSMIC and from ionosonde at Canberra
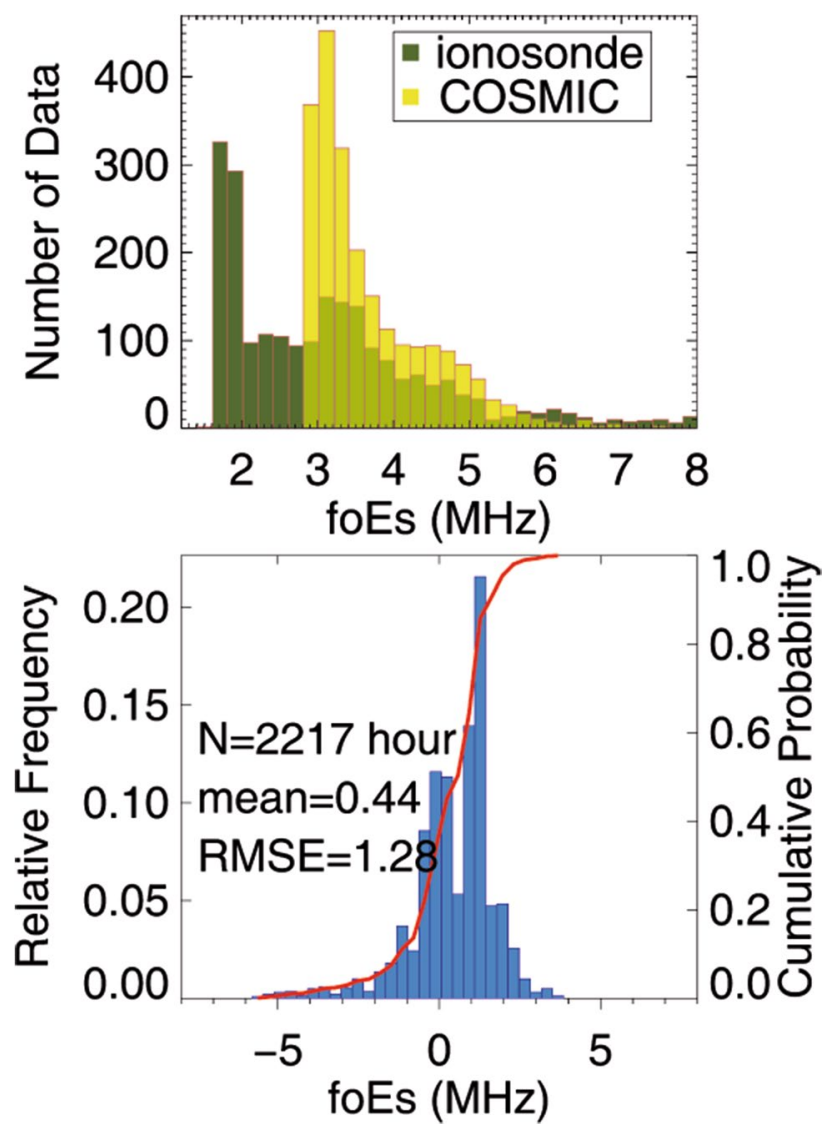

Fig. 9 Distributions of coincident hourly foEs and the statistics of hourly foEs difference between COSMIC and ionosonde at Canberra monitoring networks are also important as they provide reliable and accurate independent measurements with which to calibrate a large number of GNSS RO measurements. Differences in $\mathrm{f}_{\mathrm{o}}$ Es between COSMIC RO data and ground-based ionosonde data may result from (1) minimum threshold of $\mathrm{f}_{\mathrm{o}}$ Es observed by ionosondes and the limitation of large S4max with GNSS occultations; (2) special observational geometry of RO measurements and tangent point drift; (3) noise induced by the defocusing of GNSS signals through the reflection/refraction in E layers; (4) local ionospheric variability within an accumulated period of one hour, and an area of $5^{\circ}$ latitudes $\times 5^{\circ}$ longitudes square centered on each ground-based station.

The high-sensitivity RO technique enables the identification of weak Es layers, and the ground-based ionosondes preferentially observe the relatively intense Es layers from the strong reflected echo traces in ionograms. On the basis of COSMIC S4max observations, $66 \%$ of Es layers have a $\mathrm{f}_{\mathrm{o}} \mathrm{Es}<3.6 \mathrm{MHz}(\mathrm{S} 4 \mathrm{max}<0.4)$, which is not easily visible in ionosonde data. Global critical frequency $f_{o}$ Es data have been derived based on the FORMOSAT-3/COSMIC RO measurements correlated with ground-based ionosonde data, augmenting the limited coverage and low-frequency detection threshold of ground-based instruments ( $\mathrm{Yu}$ et al. 2020). Mathews (1998) proposed that the Es layer is considered to be sporadic due to instrumental limitation rather than physical property. A sequential sporadic E layer was often identified by incoherent scatter radar (ISR) in Arecibo, which is mostly controlled by the diurnal tide. Therefore, 'sporadic' E layers could be more frequent than we thought. The global climatology of Es layers from the RO measurements confirms that weak Es layers are not sporadic spatially (Yu et al. 2019a). A case of global simultaneous Es layers was observed from $50 \mathrm{RO}$ events and observations of seven ionosondes, which supports the idea that simultaneous Es RO events occur in a broad region (Yue et al. 2015a).

Previous studies of $\mathrm{F}$ layers have shown that the COSMIC retrieved electron density profiles are in generally good agreement with those from ionosondes both in the $\mathrm{F}_{2}$ layer peak electron density $\left(\mathrm{N}_{\mathrm{m}} \mathrm{F}_{2}\right)$ and the bottom-side electron profiles. Lei et al. (2007) analyzed 276 coincident measurements from 31 ionosondes and COSMIC. A strong correlation coefficient of $r=0.85$ was found between the COSMIC $\mathrm{N}_{\mathrm{m}} \mathrm{F}_{2}$ and those from ionosondes. Krankowski et al. (2011) analyzed electron density derived from COSMIC RO measurements over the European region. The statistical mean and standard deviation of $\mathrm{N}_{\mathrm{m}} \mathrm{F}_{2}$ differences between COSMIC and ionosonde profiles are $0.72 \%$ and $8.42 \%$. Ratovsky et al. (2017) compared the COSMIC RO measurements with those from ISR, ionosonde, and International Reference Ionosphere (IRI) model. The $\mathrm{N}_{\mathrm{m}} \mathrm{F}_{2}$ difference between COSMIC-ISR (COSMIC-ionosonde) is less than IRI-ISR (IRI-ionosonde). 
In the future, we will apply this approach to more groundbased monitoring networks containing various types of ionosondes. In comparison with independent ground-based ionosonde data from different operation organizations, a large number of RO data can be used to study the global distribution and intensity of Es layers with a small temporal/ spatial scale. These statistical analyses could also be used as a reference when scaling Es layers from ionograms.

As a COSMIC follow-on constellation, the six COSMIC-2 satellites were launched successfully on June 25, 2019. COSMIC-2 is designed to be capable of taking RO measurements from both GPS and GLONASS, which could provide 3-4 times the amount of high-quality RO data to that of COSMIC (Fong et al. 2019). The dramatically increased number of observations will advance the capability of global real-time ionospheric weather monitoring and further benefit the space weather forecasting and GNSS applications in the near future. The recent discovery of the Es layer on Mars further lays stress on the importance of the planetary Es layer to the long-distance radio communications for planetary exploration (Collinson et al. 2020).

\section{Conclusions}

The RO observations from the FORMOSAT-3/COSMIC during the period 2006-2014 are used to conduct statistical comparisons of Es layers between the scintillation index S4max occurring at altitudes of $90-130 \mathrm{~km}$ and $\mathrm{f}_{\mathrm{o}}$ Es by ionosondes. The main conclusions are as follows:

1. The GNSS RO technique can provide global estimates of Es layers as a complement to ground-based observations. RO measurements from satellites enable the identification of weak Es layers. Ionosondes preferentially observe the relatively intense Es layers from the strong reflected echo traces in ionograms.

2. Observations with $S 4 \max <0.4$ account for $66 \%$ of COSMIC S4 measurements. Small S4max values have not been used fully in previous studies of Es layers based on GNSS RO measurements, though they have a good correlation with simultaneous $\mathrm{f}_{\mathrm{o}}$ Es.

3. The mean and RMSE of the absolute difference between the $\mathrm{f}_{\mathrm{o}}$ Es derived from COSMIC S4max by the equation $f_{o} E s=2.81+2.02 \times S 4$ max and the observed foEs by ionosondes are $0 \mathrm{MHz}$ and $1.32 \mathrm{MHz}$. A total of $30.22 \%, 69.57 \%$ and $98.13 \%$ coincident foEs values have a relative difference less than $10 \%, 30 \%$ and $100 \%$. The mean and RMSE of the relative difference are $9.51 \%$ and $33.82 \%$
Acknowledgements We acknowledge the Constellation Observing System for Meteorology, Ionosphere, and Climate (COSMIC) Data Analysis and Archive Center (CDAAC) for providing COSMIC radio occultation data, the ionospheric data from the UK Solar System Data Centre (UKSSDC) at the Rutherford Appleton Laboratory, and the Chinese Meridian Project, the Solar-Terrestrial Environment Research Network, Data Center for Geophysics, Data Sharing Infrastructure of Earth System Science. The authors would like to thank the National Science and Technology Infrastructure of China. This work is supported by the National Natural Science Foundation of China (41774158, 41474129, 41421063), the open research project of CAS Large Research Infrastructures, Anhui Provincial Natural Science Foundation (1908085QD155) and the Fundamental Research Fund for the Central Universities. Bingkun Yu would like to acknowledge the Royal Society for supporting his research via the Newton International Fellowship scheme.

Data Availability The COSMIC S4max data used in this study are available from the CDAAC website: https://cdaac-www.cosmic.ucar. edu/cdaac. The ionosonde data are available from the Data Centre for Meridian Space Weather Monitoring Project (https://data.meridianpr oject.ac.cn), the Institute of Geology and Geophysics (https://space .iggcas.ac.cn), Chinese Academy of Sciences, and the UKSSDC at the Rutherford Appleton Laboratory (https://www.ukssdc.ac.uk).

Open Access This article is licensed under a Creative Commons Attribution 4.0 International License, which permits use, sharing, adaptation, distribution and reproduction in any medium or format, as long as you give appropriate credit to the original author(s) and the source, provide a link to the Creative Commons licence, and indicate if changes were made. The images or other third party material in this article are included in the article's Creative Commons licence, unless indicated otherwise in a credit line to the material. If material is not included in the article's Creative Commons licence and your intended use is not permitted by statutory regulation or exceeds the permitted use, you will need to obtain permission directly from the copyright holder. To view a copy of this licence, visit http://creativecommons.org/licenses/by/4.0/.

\section{References}

Arras C, Wickert J, Beyerle G, Heise S, Schmidt T, Jacobi C (2008) A global climatology of ionospheric irregularities derived from GPS radio occultation. Geophys Res Lett 35:L14809. https://doi. org/10.1029/2008gl034158

Arras C. (2010). A global survey of sporadic E layers based on GPS radio occultations by CHAMP, GRACE and FORMOSAT-3/ COSMIC (Doctoral dissertation, Deutsches GeoForschungsZentrum GFZ Potsdam)

Arras C, Wickert J (2018) Estimation of ionospheric sporadic E intensities from GPS radio occultation measurements. J Atmos Solar Terr Phys 171:60-63. https://doi.org/10.1016/j.jastp.2017.08.006

Bibl K, Reinisch BW (1978) The universal digital ionosonde. Radio Sci 13(3):519-530. https://doi.org/10.1029/rs013i003p00519

Briggs BH, Parkin IA (1963) On the variation of radio star and satellite scintillations with zenith angle. J Atmos Terr Phys 25(6):339-366. https://doi.org/10.1016/0021-9169(63)90150-8

Cai X, Yuan T, Eccles JV, Raizada S (2019) Investigation on the distinct nocturnal secondary sodium layer behavior above $95 \mathrm{~km}$ in winter and summer over logan, UT $41.7 \mathrm{~N}, 112 \mathrm{~W}$ and Arecibo Observatory, PR 18.3 N, 67 W. J Geophys Res Space Phys 124(11):9610-9625. https://doi.org/10.1029/2019JA026746 
Chu YH, Wang CY, Wu KH, Chen KT, Tzeng KJ, Su CL, Feng W, Plane JMC (2014) Morphology of sporadic E layer retrieved from COSMIC GPS radio occultation measurements: wind shear theory examination. J Geophys Res Space Phys 119:2117-2136. https:// doi.org/10.1002/2013ja019437

Collinson GA, McFadden J, Grebowsky J, Mitchell D, Lillis R, Withers P, Vogt MF, Benna M, Espley J, Jakosky B (2020) Constantly forming sporadic E-like layers and rifts in the Martian ionosphere and their implications for earth. Nat Astron. https://doi. org/10.1038/s41550-019-0984-8

Coster A, Komjathy A (2008) Space weather and the global positioning system. Space Weather. https://doi.org/10.1029/2008S W000400

Davis CJ, Johnson CG (2005) Lightning-induced intensification of the ionospheric sporadic E layer. Nature 435(7043):799-801. https:// doi.org/10.1038/nature03638

Davis CJ, Lo K-H (2008) An enhancement of the ionospheric sporadicE layer in response to negative polarity cloud-to-ground lightning. Geophys Res Lett 35:L05815. https://doi.org/10.1029/2007g10319 09

Dou XK, Xue XH, Li T, Chen TD, Chen C, Qiu SC (2010) Possible relations between meteors enhanced electron density layers, and sporadic sodium layers. J Geophys Res Space Phys 115:A06311. https://doi.org/10.1029/2009ja014575

Fong C-J, Chu C-H, Lin C-L, da Silva CA (2019) Toward the most accurate thermometer in space: FORMOSAT-7/COSMIC-2 constellation. IEEE Aerosp Electron Syst Mag 34(8):12-20. https:// doi.org/10.1109/maes.2019.2924133

Ma J et al (2019) Large-scale horizontally enhanced sodium layers coobserved in the midlatitude region of China. J Geophys Res Space Phys 124(9):7614-7628. https://doi.org/10.1029/2018JA026448

Haldoupis C (2011) A tutorial review on sporadic E layers. In: Abdu M, Pancheva D (eds) Aeronomy of the Earth's Atmosphere and Ionosphere. IAGA Special Sopron Book Series, vol 2. Springer, Dordrecht, pp 381-394. https://doi. org/10.1007/978-94-007-0326-1

Hsu C-T, Matsuo T, Liu J-Y (2018) Impact of assimilating the FORMOSAT-3/COSMIC and FORMOSAT-7/COSMIC-2 RO data on the midlatitude and low-latitude ionospheric specification. Earth Space Sci 5(12):875-890. https://doi.org/10.1029/2018ea000447

Hu L, Ning B, Liu L, Zhao B, Chen Y, Li G (2014) Comparison between ionospheric peak parameters retrieved from COSMIC measurement and ionosonde observation over Sanya. Adv Space Res 54(6):929-938. https://doi.org/10.1016/j.asr.2014.05.012

Jacobi C, Arras C, Geißler C, Lilienthal F (2019) Quarterdiurnal signature in sporadic $\mathrm{E}$ occurrence rates and comparison with neutral wind shear. Ann Geophys 37(2):273-288. https://doi.org/10.5194/ angeo-37-273-2019

Krankowski KG, Dmitriev AV, Suvorova AV, Shcherbakov AA, Alsatkin SS, Oinats AV (2011) Ionospheric electron density observed by FORMOSAT-3/COSMIC over the European region and validated by ionosonde data. J Geodesy 85(12):949-964. https://doi. org/10.1007/s00190-011-0481-z

Ko CP, Yeh HC (2010) COSMIC/FORMOSAT-3 observations of equatorial $\mathrm{F}$ region irregularities in the SAA longitude sector. J Geophys Res Space Phys 115:A11309. https://doi.org/10.1029/2010j a015618

Lei J et al (2007) Comparison of COSMIC ionospheric measurements with ground-based observations and model predictions: preliminary results. J Geophys Res Space Phys 112:A07308. https://doi. org/10.1029/2006JA012240

Li G, Ning B, Zhao B, Liu L, Liu JY, Yumoto K (2008) Effects of geomagnetic storm on GPS ionospheric scintillations at Sanya. J Atmos Solar Terr Phys 70(7):1034-1045. https://doi. org/10.1016/j.jastp.2008.01.003
Mathews JD (1998) Sporadic E: current views and recent progress. J Atmos Solar Terr Phys 60(4):413-435. https://doi.org/10.1016/ s1364-6826(97)00043-6

Plane JMC, Feng W, Dawkins ECM (2015) The mesosphere and metals: chemistry and changes. Chem Rev 115(10):4497-4541. https ://doi.org/10.1021/cr500501m

Plane JMC, Feng W, Gómez Martín JC, Gerding M, Raizada S (2018) A new model of meteoric calcium in the mesosphere and lower thermosphere. Atmos Chem Phys 18:14799-14811. https://doi. org/10.5194/acp-18-14799-2018

Ratovsky KG, Dmitriev AV, Suvorova AV, Shcherbakov AA, Alsatkin SS, Oinats AV (2017) Comparative study of COSMIC/FORMOSAT-3, Irkutsk incoherent scatter radar, Irkutsk Digisonde and IRI model electron density vertical profiles. Adv Space Res 60(2):452-460. https://doi.org/10.1016/j.asr.2016.12.026

Ray S, Paul A, DasGupta A (2006) Equatorial scintillations in relation to the development of ionization anomaly. Ann Geophys 24:1429 1442. https://doi.org/10.5194/angeo-24-1429-2006

Reinisch BW, Galkin IA (2011) Global ionospheric radio observatory (GIRO). Earth Planets Space 63(4):377-381. https://doi. org/10.5047/eps.2011.03.001

Resende LCA, Arras C, Batista IS, Denardini CM, Bertollotto TO, Moro J (2018) Study of sporadic E layers based on GPS radio occultation measurements and digisonde data over the Brazilian region. Ann Geophys 36:587-593. https://doi.org/10.5194/angeo $-36-587-2018$

Rishbeth H, Garriott OK (1969) Introduction to ionospheric physics. Academic, New York

Schreiner W, Rocken C, Sokolovskiy S, Syndergaard S, Hunt D (2007) Estimates of the precision of GPS radio occultations from the COSMIC/FORMOSAT-3 mission. Geophys Res Lett 34:L04808. https://doi.org/10.1029/2006g1027557

Scott CJ, Bradford J, Bell SA, Wilkinson J, Barnard L, Smith D, Tudor S (2016) Using the ionospheric response to the solar eclipse on 20 March 2015 to detect spatial structure in the solar corona. Philos Trans R Soc A Math Phys Eng Sci 374:20150216. https://doi. org/10.1098/rsta.2015.0216

Tsai LC, Su SY, Liu CH, Schuh H, Wickert J, Alizadeh MM (2018) Global morphology of ionospheric sporadic E layer from the FormoSat-3/COSMIC GPS radio occultation experiment. GPS Solut 22(4):118. https://doi.org/10.1007/s10291-018-0782-2

Wang C (2010) New chains of space weather monitoring stations in China. Space Weather 8:S08001. https://doi.org/10.1029/2010s w000603

Whalen JA (2009) The linear dependence of GHz scintillation on electron density observed in the equatorial anomaly. Ann Geophys 27(4):1755-1761. https://doi.org/10.5194/angeo-27-1755-2009

Whitehead JD (1989) Recent work on mid-latitude and equatorial sporadic-E. J Atmos Terr Phys 51(5):401-424. https://doi. org/10.1016/0021-9169(89)90122-0

Wu DL, Ao CO, Haji GA, de La Torre Juarez M, Mannucci AJ (2005) Sporadic E morphology from GPS-CHAMP radio occultation. J Geophys Res 110:A01306. https://doi.org/10.1029/2004ja010701

Xue X et al (2017) An overturning-like thermospheric Na layer and its relevance to Ionospheric field aligned irregularity and sporadic E. J Atmos Solar Terr Phys 162:151-161. https://doi.org/10.1016/j. jastp.2016.12.006

Xun Y, Yang G, Wang J, Du L, Wang Z, Jiao J, Cheng X, Li F, Zou X (2020) The comprehensive study of low thermospheric sodium layers during the 24th solar cycle. Atmosphere 11(3):284. https ://doi.org/10.3390/atmos11030284

Yeh KC, Liu C-H (1982) Radio wave scintillations in the ionosphere. Proc IEEE 70:324-360. https://doi.org/10.1109/proc.1982.12313

Yeh W-H, Huang C-Y, Hsiao T-Y, Chiu T-C, Lin C-H, Liou Y-A (2012) Amplitude morphology of GPS radio occultation data for 
sporadic-E layers. J Geophys Res Space Phys 117:A11304. https ://doi.org/10.1029/2012ja017875

Yu B, Xue X, Lu G, Ma M, Dou X, Qie X, Ning B, Hu L, Wu J, Chi Y (2015) Evidence for lightning-associated enhancement of the ionospheric sporadic E layer dependent on lightning stroke energy. J Geophys Res Space Phys 120(10):9202-9212. https:// doi.org/10.1002/2015ja021575

Yu B, Xue X, Yue X, Yang C, Yu C, Dou X, Ning B, Hu L (2019) The global climatology of the intensity of the ionospheric sporadic E layer. Atmos Chem Phys 19(6):4139-4151. https://doi. org/10.5194/acp-19-4139-2019

Yu B et al (2019) The intensification of metallic layered phenomena above thunderstorms through the modulation of atmospheric tides. Sci Rep 9(1):1-13. https://doi.org/10.1038/s41598-019-54450-1

Yu B, Scott C, Xue X, Yue X, Dou X (2020) Derivation of global ionospheric Sporadic E critical frequency (foEs) data from the amplitude variations in GPS/GNSS radio occultations. R Soc Open Sci 7(7):200320. https://doi.org/10.1098/rsos.200320

Yuan T, Wang J, Cai X, Sojka J, Rice D, Oberheide J, Criddle N (2014) Investigation of the seasonal and local time variations of the high-altitude sporadic Na layer (Nas) formation and the associated midlatitude descending E layer (Es) in lower E region. J Geophys Res Space Phys 119(7):5985-5999. https://doi.org/10.1002/2014ja019942

Yue X, Schreiner WS, Pedatella N, Anthes RA, Mannucci AJ, Straus PR, Liu JY (2014) Space weather observations by GNSS radio occultation: from FORMOSAT-3/COSMIC to FORMOSAT-7/ COSMIC-2. Space Weather 12(11):616-621. https://doi. org/10.1002/2014sw001133

Yue X, Schreiner WS, Zeng Z, Kuo YH, Xue X (2015) Case study on complex sporadic E layers observed by GPS radio occultations. Atmos Meas Tech 8(1):225-236. https://doi.org/10.5194/ amt-8-225-2015

Yue X, Schreiner WS, Kuo YH, Lei J (2015) Ionosphere equatorial ionization anomaly observed by GPS radio occultations during 2006-2014. J Atmos Solar Terr Phys 129:30-40. https://doi. org/10.1016/j.jastp.2015.04.004

Yue X, Schreiner WS, Pedatella NM, Kuo YH (2016) Characterizing GPS radio occultation loss of lock due to ionospheric weather. Space Weather 14(4):285-299. https://doi.org/10.1002/2015s w001340

Zeng Z, Sokolovskiy S (2010) Effect of sporadic E clouds on GPS radio occultation signals. Geophys Res Lett 37:L18817. https:// doi.org/10.1029/2010gl044561

Publisher's Note Springer Nature remains neutral with regard to jurisdictional claims in published maps and institutional affiliations.

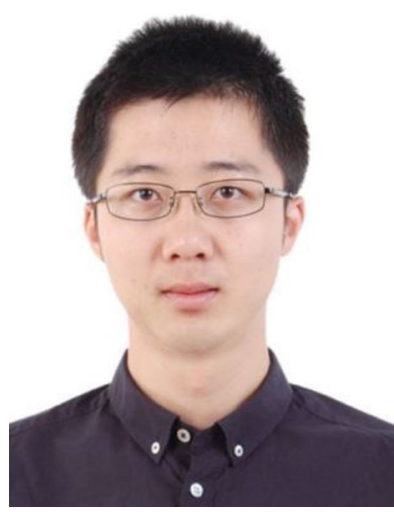

Bingkun $\mathrm{Yu}$ is a postdoctoral research fellow in the Department of Meteorology, University of Reading. He received his $\mathrm{Ph}$.D. degree at the University of Science and Technology of China in 2018. He was awarded the Newton International Fellowship by the Royal Society of the United Kingdom in 2018. His research currently focuses on the earth's upper atmosphere, ionosphere and the space-weather impact on the whole-atmosphere coupling via lightning.

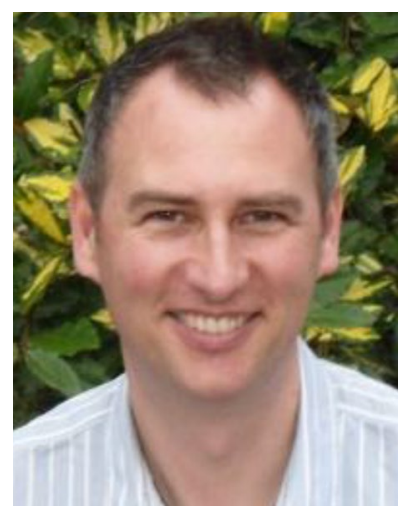

Christopher J. Scott is a Professor of Space and Atmospheric Physics in the Department of Meteorology, University of Reading. He received his Ph.D. in Physics and Astronomy from the University of Southampton in 1993. He studies the ionosphere, thermosphere and the aurora. He is a co-Investigator on the NASA STEREO mission, studying the solar wind and its impact on Earth. He is an enthusiastic citizen science advocate and PI for www.solarstormwatch.com.

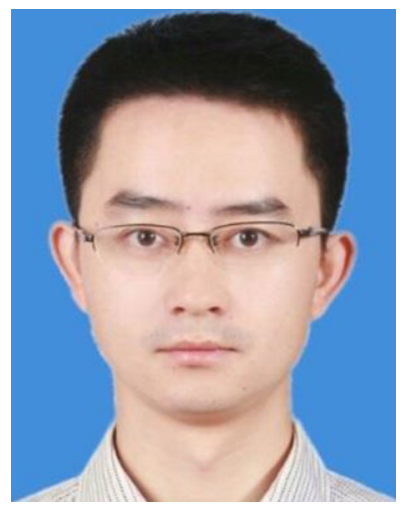

Xianghui Xue is a professor in the School of Earth and Space Science at the University of Science and Technology of China. He received his Ph.D. in space physics from the University of Science and Technology of China. $\mathrm{He}$ received the Chinese National Science Fund for Excellent Young Scholars in 2013. His scientific interests include lidar applications in atmospheric remote sensing, atmospheric dynamics in the mesosphere and lower thermosphere.

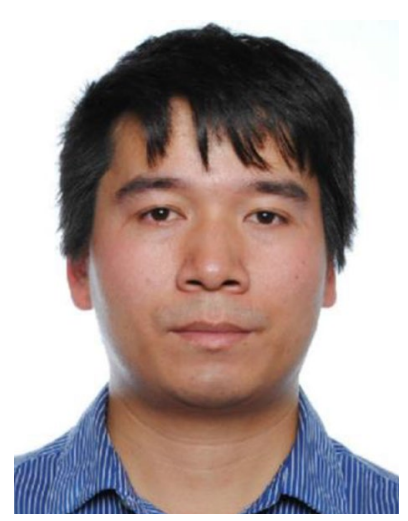

Xinan Yue is a research professor at IGGCAS. He received the Ph.D. degree in space physics from the University of CAS in 2008. He used to be a Project Scientist in the UCAR COSMIC Program Office and responsible for ionospheric data process and evaluation. Currently, he is focusing on the development of a phase array incoherent scattering radar in low latitude China. His scientific interests include ionospheric-thermospheric modeling, data assimilation, GNSS applications, remote sensing, and space weather.

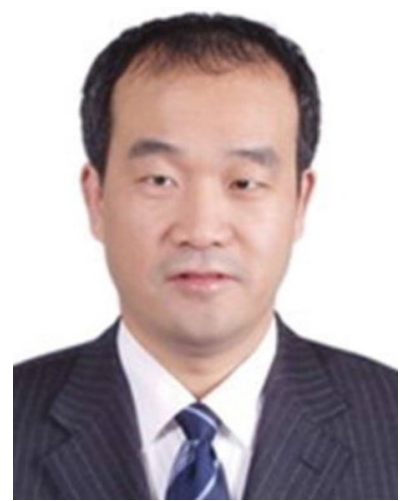

Xiankang Dou is a professor in the CAS Key Laboratory of Geospace Environment, University of Science and Technology of China. He received the Chinese National Science Fund for Distinguished Young Scholars in 2010 and was selected as a member of the Chinese Academy of interests include dynamics and waves in the stratosphere, mesosphere, and lower thermosphere, laser remote sensing technology and lidar atmospheric sensing. Sciences in 2017. His scientific 